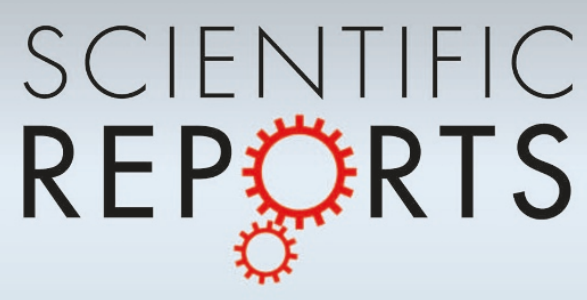

OPEN

SUBJECT AREAS:

PHOTONIC DEVICES

SOLAR CELLS

ELECTRONIC DEVICES

ELECTRONIC PROPERTIES AND

MATERIALS

Received

2 April 2013

Accepted

17 May 2013

Published

11 June 2013

Correspondence and requests for materials should be addressed to V.G. (drvinaygupta@ netscape.net) or A.J.H. (ajhe@physics.ucsb. edu)

\section{Barium: An Efficient Cathode Layer for Bulk-heterojunction Solar Cells}

\author{
Vinay Gupta ${ }^{1,2}$, Aung Ko Ko Kyaw' ${ }^{1}$ Dong Hwan Wang' ${ }^{1}$ Suresh Chand ${ }^{2}$, Guillermo C. Bazan ${ }^{1}$ \\ \& Alan J. Heeger ${ }^{1}$
}

${ }^{1}$ Center for Polymers and Organic Solids, University of California at Santa Barbara Santa Barbara, California 93106-5090, USA, ${ }^{2}$ Organic and hybrid solar cell group, CSIR- National Physical Laboratory Dr. K. S. Krishnan Marg, New Delhi, 110012 , India.

We report Barium $(\mathrm{Ba})$ cathode layer for bulk-heterojunction solar cells which enhanced the fill factor (FF) of p-DTS $\left(\mathrm{FBTTh}_{2}\right)_{2} / \mathrm{PC}_{71} \mathrm{BM} \mathrm{BHJ}$ solar cell up to $75.1 \%$, one of the highest value reported for an organic solar cell. The external quantum efficiency exceeds $80 \%$. Analysis of recombination mechanisms using the current-voltage $(J-V)$ characteristics at various light intensities in the BHJ solar cell layer reveals that Ba prevents trap assisted Shockley-Read-Hall (SRH) recombination at the interface and with different thicknesses of the $\mathrm{Ba}$, the recombination shifts towards bimolecular from monomolecular. Moreover, $\mathrm{Ba}$ increases shunt resistance and decreases the series resistance significantly. This results in an increase in the charge collection probability leading to high FF. This work identifies a new cathode interlayer which outclasses the all the reported interlayers in increasing FF leading to high power conversion efficiency and have significant implications in improving the performance of $\mathrm{BHJ}$ solar cells.

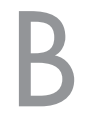

ulk-heterojunction (BHJ) organic solar cells are of significant interest for sun-light harvesting devices because of the potential for low cost of manufacturing of large areas through roll-to-roll coating technologies on flexible substrates ${ }^{1-6}$. The power conversion efficiency PCE of a solar cell is determined by three key parameters i.e. open circuit voltage $\left(\mathrm{V}_{\mathrm{oc}}\right)$, the short circuit current $\left(\mathrm{J}_{\mathrm{sc}}\right)$ and the fill factor $(\mathrm{FF})$. $\mathrm{V}_{\mathrm{oc}}$ is correlated with the energy difference between the highest occupied molecular orbital (HOMO) of the donor (conjugated polymer or small molecule) and the lowest unoccupied molecular orbital (LUMO) of the acceptor (typically a fullerene derivative) whereas $\mathrm{J}_{\mathrm{sc}}$ is determined by the absorption spectrum and absorption depth of the organic donor and the transport of photogenerated carriers through the morphology of the film. In order to achieve high $\mathrm{J}_{\mathrm{sc}}$ and $\mathrm{V}_{\mathrm{oc}}$ in $\mathrm{BHJ}$ solar cells, low band gap polymers and solution processable small molecules (for use in Tandem Cells) have been developed with PCE exceeding $7 \%^{7-10}$. It is, however, necessary to find ways to improve the FF for achieving higher PCE values ${ }^{11}$.

Interlayers play a significant role in improving the FF by minimizing the contact resistance and charge recombination and for enabling efficient extraction (or blocking) of holes and electrons. The use of interlayers circumvents the direct contact between the photoactive donor (polymer or small molecule) and electrodes where high densities of carrier traps and interface dipoles can hinder efficient charge collection. Consequently, a significant effort in interfacial engineering has developed using metal oxides $\left(\mathrm{MoO}_{3}, \mathrm{CsCO}_{3}, \mathrm{TiO}_{\mathrm{x}}, \mathrm{NiO}\right.$, $\mathrm{WO}_{3}, \mathrm{~V}_{2} \mathrm{O}_{5}$ and $\left.\mathrm{ZnO}, \mathrm{Ca}\right)^{12-18}, \mathrm{LiF}^{19,20}$, bathocuproine $(\mathrm{BCP})^{21,22}$, and self-assembled monolayers (SAMs) ${ }^{23}$. Although several metal oxides have been studied as anode interlayer or hole transport layer (HTL), poly $(3,4-$ ethylene dioxythiophene):(polystyrene sulfonic acid) (PEDOT:PSS) is most commonly used as the anode interlayer or hole transporting layer (HTL) due to its high work function and compatibility with ITO. However, the cathode interlayer remains an open area for research due to unavailability of low work function materials that can effectively block holes. Recently, conjugated polyelectrolytes (CPEs), which are conjugated polymers with pendent group bearing ionic functionalities ${ }^{24-27}$, have been shown to improve the PCE to values in excess of $8 \% \%^{6,28}$,

In this work, we demonstrate that pure Barium (Ba) metal (capped by Aluminum) as the cathode layer improves the FF to $75.1 \%$. This high FF BHJ solar cell is based on the small molecule donor, 7,7'-(4,4-bis(2ethylhexyl)-4H-silolo[3,2-b:4,5-b']dithiophene-2,6-diyl)bis(6-fluoro-4-(5'-hexyl-[2,2'-bithiophen]-5-yl)benzo $[c][1,2,5]$ thiadiazole), $\left(\mathrm{p}-\mathrm{DTS}\left(\mathrm{FBTTh}_{2}\right)_{2}\right)^{9}$. With the insertion of a $10-20 \mathrm{~nm}$ thick Ba layer capped by Aluminum $(100 \mathrm{~nm})$, the FF increases from $56 \%$ to $74.2 \sim 75.1 \%$ and the PCE increases from $5.86 \%$ to 7.78 8.57\%. The results are compared with state-of-the-art $\mathrm{Ca} / \mathrm{Al}$ devices for the same thicknesses. 


\section{Results}

The molecular structure of p-DTS $\left(\mathrm{FBTTh}_{2}\right)_{2}$ and $\mathrm{PC}_{71} \mathrm{BM}$, the device structure and the energy levels of the components used in the devices are shown in Figure 1a, b, respectively. A blend of pDTS(FBTTh $)_{2}$ and [6-6]-phenyl $\mathrm{C}_{71}$ butyric acid methyl ester $\left(\mathrm{PC}_{71} \mathrm{BM}\right)$ in $6: 4$ ratio is used as the active layer for device fabrication as detailed in method section. We used different thicknesses of $\mathrm{Ba}$ $(10,20,30 \mathrm{~nm})$ between $\mathrm{p}$-DTS $\left(\mathrm{FBTTh}_{2}\right)_{2}: \mathrm{PC}_{71} \mathrm{BM}$ photoactive blend and the Aluminum (100 $\mathrm{nm}$ ) capping layer and studied the device performance.

Figure $2 \mathrm{a}$ and Table 1 shows the current density versus voltage $(J-$ $V)$ characteristics of the SM BHJ solar cells under $100 \mathrm{~mW} / \mathrm{cm}^{2}(\mathrm{AM}$ $1.5 \mathrm{G})$ illumination and an aperture area of $4.5 \mathrm{~mm}^{2}$ with a device configuration ITO $\left(20 \Omega /\right.$ sq)/PEDOT:PSS/p-DTS $\left(\mathrm{FBTTh}_{2}\right)_{2}: \mathrm{PC}_{71}$ $\mathrm{BM} /(\mathrm{Ba}) / \mathrm{Al}$ with $\mathrm{Ba}$ interlayer thicknesses of $0 \mathrm{~nm} .10 \mathrm{~nm}, 20 \mathrm{~nm}$ and $30 \mathrm{~nm}$. The control device (without $\mathrm{Ba}$ interlayer) exhibited $\mathrm{J}_{\mathrm{sc}}=13.51 \mathrm{~mA} / \mathrm{cm}^{2}, \mathrm{~V}_{\mathrm{oc}}=0.779 \mathrm{~V}$, and a $\mathrm{FF}=56 \%$. These values correspond to a $\mathrm{PCE}=5.86 \%$. After inserting the Ba cathode layer $(10 \mathrm{~nm})$, the device performance improves to $\mathrm{FF}=75.1 \%$. and PCE $=7.78 \%$. For similar thickness of Ca layer, the device exhibited $\mathrm{J}_{\mathrm{sc}}=$ $13.90 \mathrm{~mA} / \mathrm{cm}^{2}, \mathrm{FF}=64.6 \%$ and a PCE $=7.01 \%$. An increase in the thickness of $\mathrm{Ba}$ cathode interlayer to $20 \mathrm{~nm}$ improves the PCE to $8.57 \%$ with $\mathrm{FF}=74.2 \%$, whereas $20 \mathrm{~nm} \mathrm{Ca}$ leads to a $\mathrm{PCE}=7.58 \%$ with $\mathrm{FF}=67.5 \%$. Most of the increase in the performance of the $20 \mathrm{~nm}$ Ba device comes from the $\approx 10.7 \%$ and $\approx 32.5 \%$ enhancements in $\mathrm{J}_{\mathrm{sc}}$ and FF values, respectively. A further increase in the Ba thickness to $30 \mathrm{~nm}$, causes the FF to decrease to $68.8 \%$ with PCE $=8.13 \%$, whereas $30 \mathrm{~nm}$ Ca gives $\mathrm{PCE}=7.36 \%$ with $\mathrm{FF}=62.7 \%$ (Table 1). Figure $2 \mathrm{~b}$ and in () of the Table 1 , the current density versus voltage $(J-V)$ characteristics of p-DTS $\left(\mathrm{FBTTh}_{2}\right)_{2} / \mathrm{PC}_{71} \mathrm{BM}$ $\mathrm{BHJ}(10 \mathrm{~nm} \mathrm{Ba})$ measured without aperture, is shown for comparison. The PCE jumped to $9.02 \%$ for $10 \mathrm{~nm} \mathrm{Ba}$, respectively. The Fill factor is not changed much. One needs to be cautious that in the absence of an aperture, the entire film is illuminated. Due to that, a significant number of charge carriers outside of the area of the electrode would also flow towards the electrode and contribute to the current and the actual area contributing to the photocurrent would be larger than the Al-electrode area. Therefore the PCE values can be exaggerated.
As shown in the Figure $2 \mathrm{a}$ (inset) and 3a, the insertion of the $\mathrm{Ba}$ layer $(10 \mathrm{~nm})$ reduces the series resistance from $10 \Omega \mathrm{cm}^{2}$ to $0.9 \Omega \mathrm{cm}^{2}$ and increases the shunt resistance from $0.5 \mathrm{k} \Omega \mathrm{cm}^{2}$ to $5 \mathrm{k} \Omega \mathrm{cm}^{2}$, which leads to $75.1 \% \mathrm{FF}$. for $20 \mathrm{~nm} \mathrm{Ba}$, the series resistance $=1.2 \Omega \mathrm{cm}^{2}$ and shunt resistance $=10.6 \mathrm{k} \Omega \mathrm{cm}^{2}$, are obtained, leading to $\mathrm{PCE}=8.57 \%$. A further increase in the thickness of $\mathrm{Ba}$ to $30 \mathrm{~nm}$ leads to a large increase in the series resistance to $1.2 \Omega \mathrm{cm}^{2}$ and decrease in the shunt resistance to $2.9 \mathrm{k} \Omega \mathrm{cm}^{2}$, leading to a drop in the PCE to $8.13 \%$. Therefore, the resistance change due to the $\mathrm{Ba}$ layer plays pivotal role in increasing the FF and PCE. The dark J-V curves (inset of Figure 2a) also show excellent diode characteristics with very low leakage current and high rectification ratio (forward to reverse factor of approx. 100). The improvement in $\mathrm{J}_{\mathrm{sc}}$ is also in agreement with the external quantum efficiency (EQE) measurements (Figure $3 \mathrm{~b}$ ). The EQE value exceeds $80 \%$ over the wavelength range $600 \mathrm{~nm}$ and $700 \mathrm{~nm}$ for devices with $20 \mathrm{~nm} \mathrm{Ba}$.

\section{Discussion}

To understand the increased $\mathrm{FF}$ and $\mathrm{J}_{\mathrm{sc}}$, the recombination kinetics were probed by measurements of the light intensity dependence of the $J-V$ characteristics ${ }^{29,30}$. Such studies are known to provide information on the relative importance of different recombination mechanisms such as Shockley-Read-Hall (SRH) monomolecular recombination and bimolecular recombination ${ }^{29-37}$. We measured the $J-V$ characteristics in the SM BHJ solar cells at different illumination intensities (100 to $0.1 \mathrm{~mW} / \mathrm{cm}^{2}$ ) without $\mathrm{Ba}$ and with different thicknesses of the Ba layer. Figures $4 a, b$ show the J-V curve of the DTS $\left(\text { FBTTh }_{2}\right)_{2}: \mathrm{PC}_{71} \mathrm{BM}$ device without and with the $20 \mathrm{~nm} \mathrm{Ba}$ layer, respectively. The Ba layer affects the shape of $J-V$ curve which is strongly correlated with the recombination mechanism ${ }^{35}$. At open circuit (low external bias), bimolecular recombination is clearly dominant. Analysis of the recombination mechanism at short circuit is complicated by the simultaneous sweep-out during recombination. Because the sweep-out is approximately linear in intensity, recombination shows up only as a small deviation from linearity. With the Ba layer (Figure 4b), the photocurrent saturates quickly at low reversed biases: Nearly $100 \%$ of the photogenerated carriers are swept out prior to recombination. However, the current saturation rate is slower without the $\mathrm{Ba}$ layer (Figure $4 \mathrm{a}$ ), and the

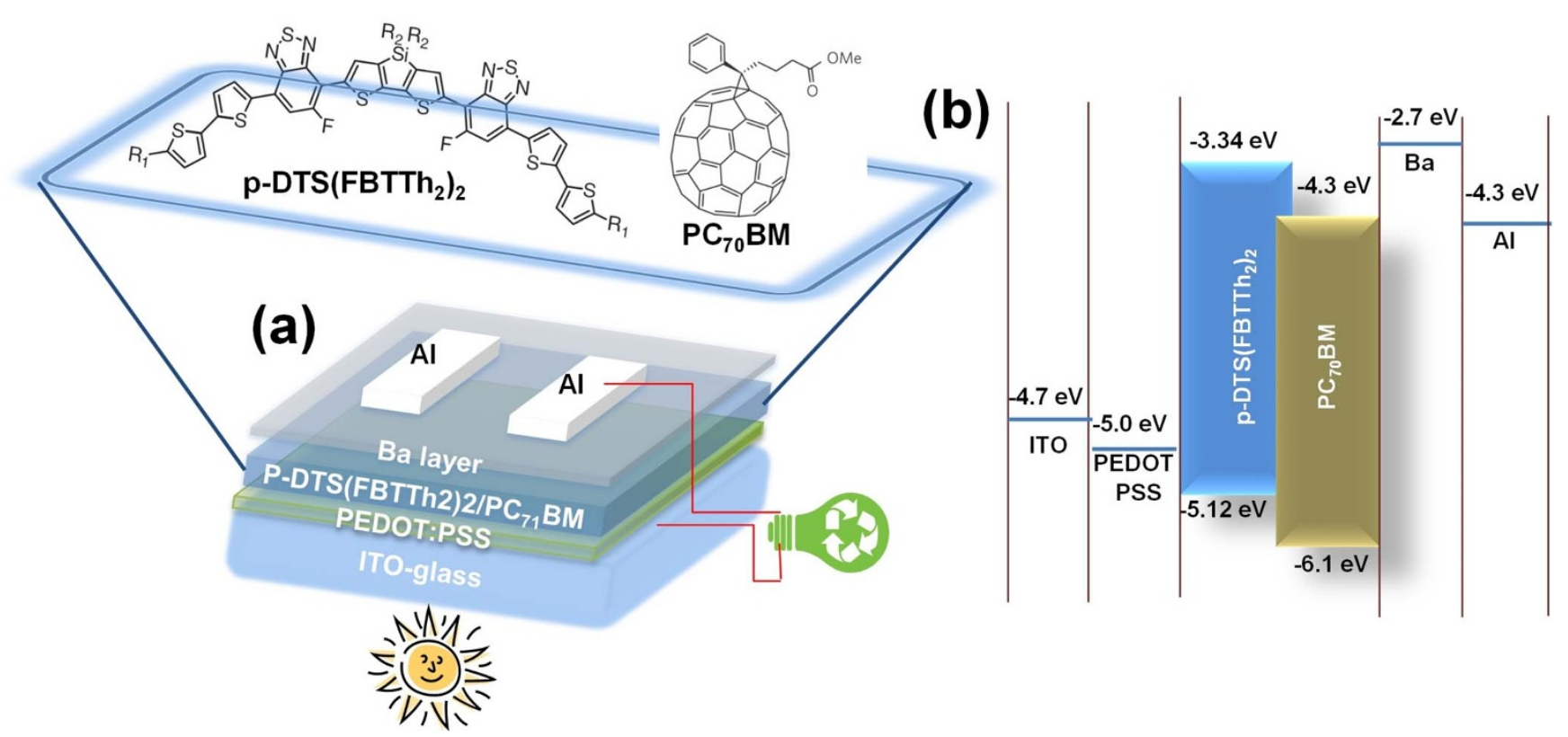

Figure $1 \mid$ (a) The device structure of the inverted p-DTS $\left(\mathrm{FBTTh}_{2}\right)_{2}: \mathrm{PC}_{71} \mathrm{BM}$ solar cell. Inset shows the molecular structures of p-DTS(FBTTh $)_{2}$ and $\mathrm{PC}_{71} \mathrm{BM}$. (b) Energy level diagram of SM-BHJ solar cells with sequential layers of ITO/PEDOT:PSS/p-DTS(FBTTh $)_{2}: \mathrm{PC}_{71} \mathrm{BM} \mathrm{BHJ/Ba} \mathrm{layer/Al} \mathrm{cathode.}$ 

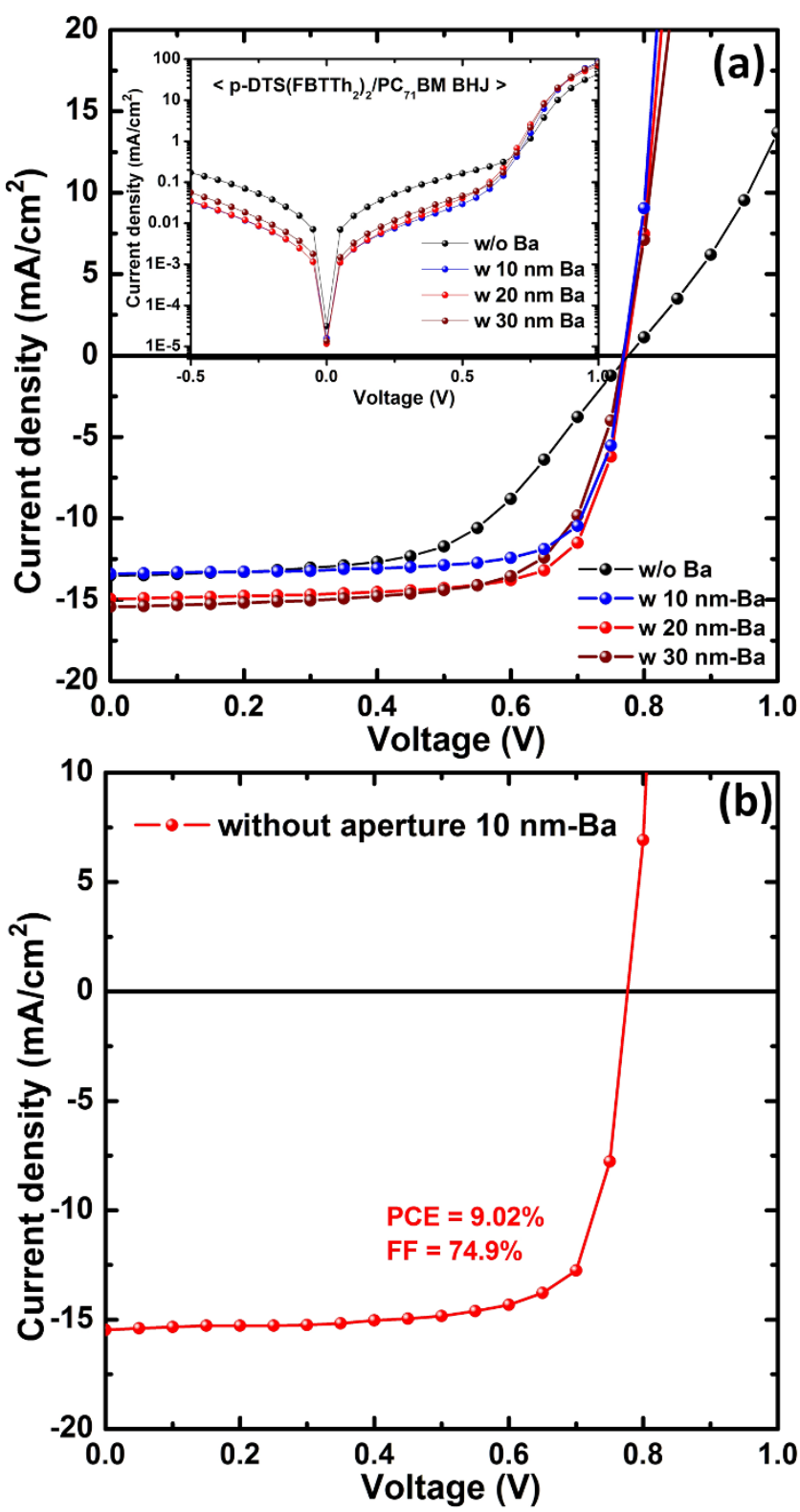

Figure $2 \mid J-V$ characteristics of the p-DTS $\left(\mathrm{FBTTh}_{2}\right)_{2} / \mathrm{PC}_{71} \mathrm{BM} \mathrm{BHJ}$ solar cells with various $\mathrm{Ba}$ thicknesses under AM $1.5 \mathrm{G}$ irradiation at 100 $\mathrm{mW} / \mathrm{cm}^{2}$ (a) with aperture and (inset) is the dark current. (b) without aperture. photogenerated carries are not swept-out completely near $\mathrm{J}_{\mathrm{sc}}$. Thus, the Ba layer favors the sweep-out in competition with recombination, thus suppressing recombination and leading to higher FF.

Insight into the recombination mechanism can be obtained by measuring $\mathrm{V}_{\mathrm{oc}}$ as a function of the light intensity ${ }^{29,37}$. At $\mathrm{V}_{\mathrm{oc}}$, the photocurrent is zero, and all photogenerated carriers recombine within the cell. Thus, recombination studies at $\mathrm{V}_{\mathrm{oc}}$ can provide detailed information of various mechanisms. The $\mathrm{V}_{\mathrm{oc}}$ and light intensity (I) are correlated by the following expression

$$
V_{o c}=\frac{1}{e}\left(E_{L U M O}^{\text {Fullurene }}-E_{\text {HOMO }}^{\text {Polymer }}-\Delta\right)-\frac{k T}{e} \ln \left(\frac{n_{e} n_{h}}{N_{c}^{2}}\right)
$$

where $\mathrm{n}_{\mathrm{e}} \mathrm{n}_{\mathrm{h}}$ is proportional to the light intensity, $e$ is the elementary charge, $k$ is the Boltzman constant, $T$ is temperature in Kelvin, $n_{e}$ and $n_{h}$ are the electron and hole densities in the fullerene and polymer domains at open circuit, and $N_{c}$ is the effective density of states and $\Delta$ represents the relatively small band tailing to energy below the acceptor LUMO. Thus, for bimolecular recombination ${ }^{29}$

$$
\delta V_{o c}=\left(\frac{k T}{e}\right) \ln (I)+\text { const. }
$$

where I is the incident light intensity, This implies that the slope of $V_{o c}$ versus $\ln (I)$ is equal to $k T / e$ for bimolecular recombination. In the case of monomolecular SRH recombination, a stronger dependence of $\mathrm{V}_{\mathrm{oc}}$ on the light intensity is observed and in that case $\mathrm{n}_{\mathrm{e}}$ and $\mathrm{n}_{\mathrm{h}}$ (at $\mathrm{V}_{\mathrm{oc}}$ ) would each be proportional to the intensity and the slope of $V_{o c}$ versus $\ln (\mathrm{I})$ is equal to $2 k T / e^{29}$.

Figure 5a shows the $\mathrm{V}_{\text {oc }}$ versus light intensity relationship for devices with $0,10 \mathrm{~nm}, 20 \mathrm{~nm}$ and $30 \mathrm{~nm}$ thick Ba layers. For SM $\mathrm{BHJ}$ without $\mathrm{Ba}$, a strong dependence of $\mathrm{V}_{\mathrm{oc}}$ on light intensity is observed where the recombination at the open circuit is a combination of monomolecular (slope $=1.99 \mathrm{kT} / \mathrm{e}$ ) and bimolecular processes (slope $=1.32 \mathrm{kT} / \mathrm{e}$ ). The SRH recombination due to trap states can be clearly observed at low light intensities $(\approx 1 \mathrm{~mW} /$ $\mathrm{cm}^{2}$ ), where the cell's efficiency becomes highly dependent on the bias and light intensity ( layer significantly reduces the trap assisted recombination with reduced slopes of $1.21 \mathrm{kT} / \mathrm{e}$ and $1.38 \mathrm{kT} / \mathrm{e}$ at high and low light intensities, respectively. A further increase in the Ba thickness to 20 and $30 \mathrm{~nm}$ effectively blocked monomolecular recombination with the slope nearly equal to $\mathrm{kT} / \mathrm{e}$. This is consistent with the decreased series resistance after insertion of Ba layer (Table 1) which is a direct evidence of the role of $\mathrm{Ba}$ to improve the device performance. Now we look into the charge recombination kinetics at short circuit for SM BHJ and the $20 \mathrm{~nm}$ Ba SM BHJ. The $\mathrm{J}_{\mathrm{sc}}$ can be correlated to illumination intensity $(I)$ by,

Table 1 Device efficiency and electrical parameters of p-DTS(FBTTh $)_{2} / \mathrm{PC}_{71} \mathrm{BM} S \mathrm{SM}-\mathrm{BHJ}$ solar cells without Ba and with different thicknesses of Ba layer

\begin{tabular}{lccccccc} 
Thickness $(\mathrm{nm})$ & Type of layer & $V_{\text {OC }}[\mathrm{V}]$ & $J_{S C}\left[\mathrm{~mA} / \mathrm{cm}^{2}\right]$ & $\mathrm{FF}[\%]$ & $\mathrm{PCE}[\%]$ & $\mathrm{R}_{\mathrm{s}}\left[\Omega \mathrm{cm}^{2}\right]$ & $\mathrm{R}_{\text {sh }}\left[\mathrm{k} \Omega \mathrm{cm}^{2}\right]$ \\
\hline 0 & - & 0.776 & 13.51 & 56.0 & 5.86 & 10.0 & 0.5 \\
& & $(0.778)$ & $(15.63)$ & $(55.8)$ & $(6.78)$ & $(10.5)$ & $(0.4)$ \\
10 & $\mathrm{Ba}$ & 0.772 & 13.40 & 75.1 & 7.78 & 0.9 & 5.0 \\
& & $(0.779)$ & $(15.47)$ & $(74.9)$ & $(9.02)$ & $(1.0)$ & $(4.8)$ \\
20 & $\mathrm{Ca}$ & 0.775 & 13.45 & 66.7 & 6.95 & 6.1 & 1.2 \\
& $\mathrm{Ba}$ & 0.773 & 14.96 & 74.2 & 8.57 & 1.2 & 10.6 \\
30 & $\mathrm{Ca}$ & 0.778 & 14.21 & 67.1 & 7.41 & 2.4 & 1.8 \\
& $\mathrm{Ba}$ & 0.768 & 15.43 & 68.8 & 8.13 & 1.7 & 2.9 \\
& $\mathrm{Ca}$ & 0.775 & 15.16 & 62.7 & 7.36 & 3.9 & 0.8 \\
\hline
\end{tabular}

Values shown in the () are without aperture. 

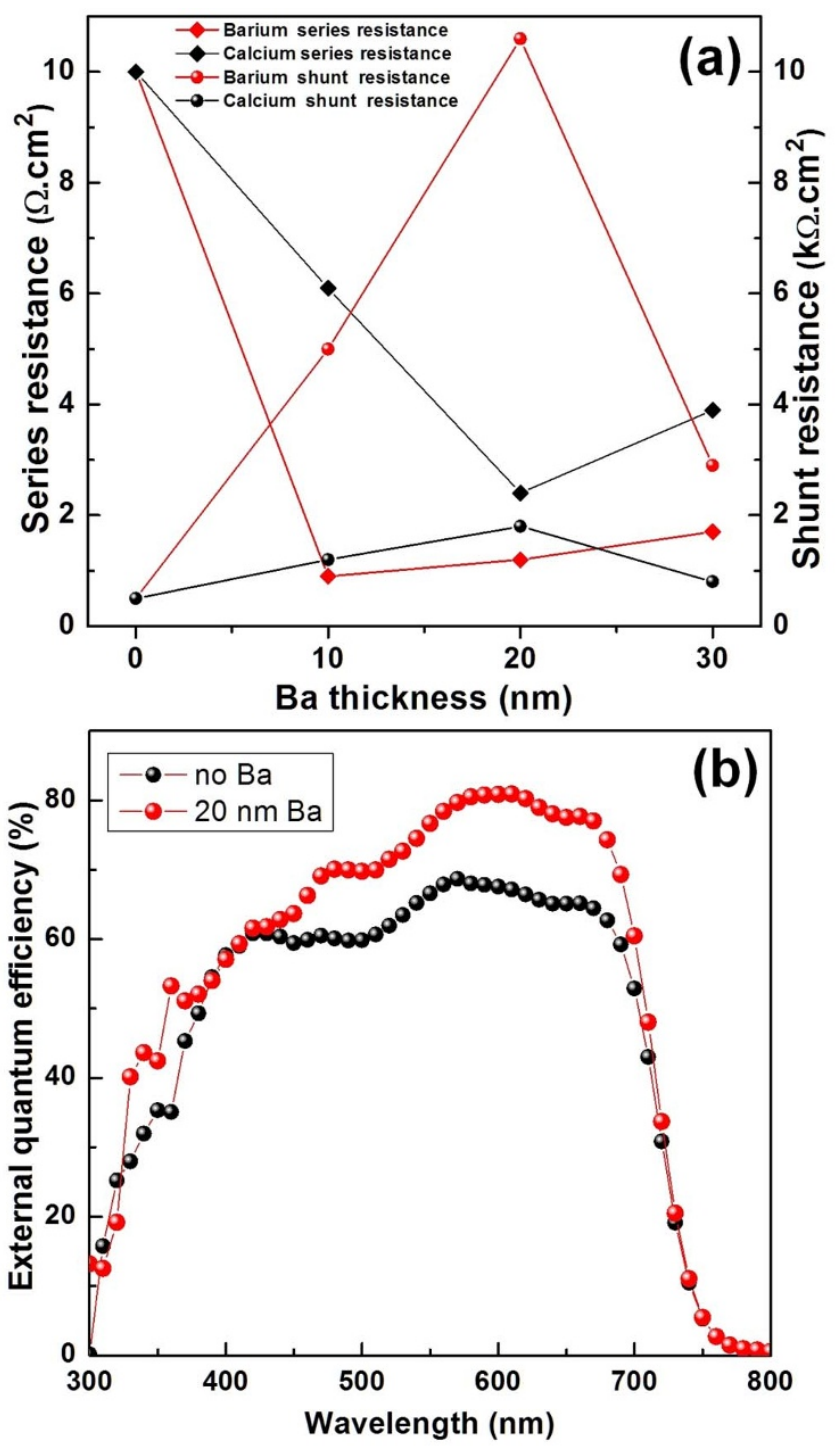

Figure $3 \mid$ (a) Electrical resistance parameters of the p-DTS $\left(\text { FBTTh }_{2}\right)_{2} /$ $\mathrm{PC}_{71} \mathrm{BM} \mathrm{BHJ}$ solar cells as a function of thickness. (b) External quantum efficiency (EQE) spectra of p-DTS(FBTTh $)_{2} / \mathrm{PC}_{71} \mathrm{BM} \mathrm{BHJ}$ solar cells without $\mathrm{Ba}$ and with $\mathrm{Ba} 20 \mathrm{~nm}$.

$$
J_{S C} \propto I^{\alpha}(\alpha \leq 1)
$$

At short circuit, the bimolecular recombination should be minimum ( $\alpha \approx 1$ ) for maximum carrier sweep out. Any deviation from $\alpha \approx 1$ implies bimolecular recombination ${ }^{38-40}$. Figure $5 \mathrm{~b}$ shows $\mathrm{J}_{\mathrm{sc}}$ vs. $I$ on $\log$-log scale fitted using the power law described above. The fitting of the data yield $\alpha=0.914$ for SM BHJ, which can be attributed to bimolecular recombination. After $20 \mathrm{~nm}$ Ba deposition, $\alpha$ is 0.993, which imply that bimolecular recombination is close to minimum. This is correlated with observed increase in the shunt resistance (Table 1) and high collection probability at short circuit. Another factor that can also contribute to the faster sweep put is the internal voltage $\left(\mathrm{V}_{\text {int }}\right)$. In the dark (Inset of Figure 2a), the device with $\mathrm{Ba}$ layer shows a turn-on voltage of $\approx 0.65 \mathrm{~V}$ whereas it is only $\approx 0.45 \mathrm{~V}$ for control device, indicating a significant increase in the built-in potential $\left(\mathrm{V}_{\mathrm{bi}}\right)$ due to the lower work function of the $\mathrm{Ba}(2.7 \mathrm{eV})$, compared to $\mathrm{Al}(4.3 \mathrm{eV})$. A larger $\mathrm{V}_{\mathrm{bi}}$ means a larger $\mathrm{V}_{\mathrm{int}}$, which might also support the charge carriers escape shallow traps. The hole blocking efficiency for devices with $0,10 \mathrm{~nm}, 20 \mathrm{~nm}$ and $30 \mathrm{~nm}$ thick $\mathrm{Ba}$ layer are shown in Figure 6. The devices without $\mathrm{Ba}$ layer nearly break down at $3 \mathrm{~V}$ reverse bias whereas devices with
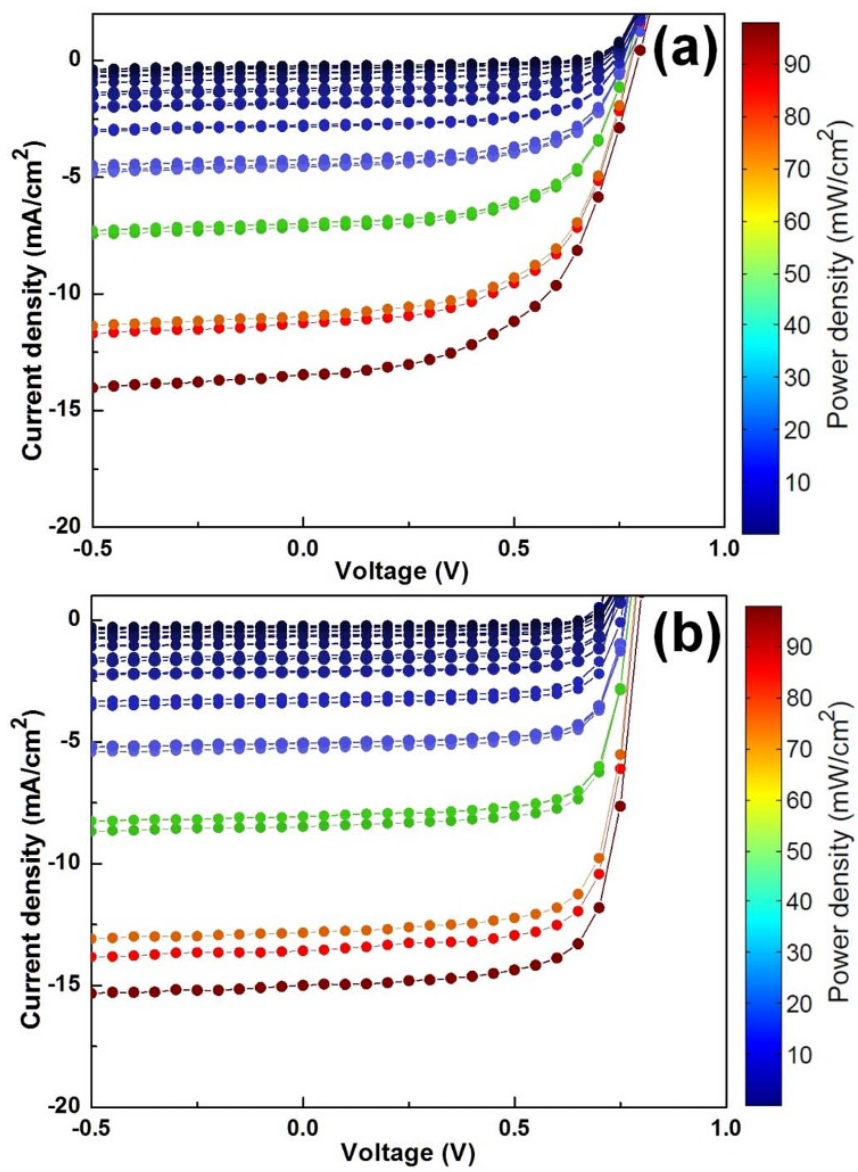

Figure $4 \mid J-V$ characteristics of p-DTS(FBTTh $)_{2}: \mathrm{PC}_{71} \mathrm{BM}$ solar cells with (a) $0 \mathrm{~nm} \mathrm{Ba} \mathrm{\&} \mathrm{(b)} 20 \mathrm{~nm} \mathrm{Ba}$, under various light intensities ranging from $100 \mathrm{~mW} / \mathrm{cm}^{2}$ to $0.5 \mathrm{~mW} / \mathrm{cm}^{2}$.

Ba show very stable photocurrent generation at reverse bias. All the encapsulated Ba devices are stable and show no sign of degradation over a period of two weeks.

In conclusion, the $\mathrm{Ba}$ interlayer between the Aluminum and organic active layers significantly improve the FF and hence the PCE of the SM BHJ. The maximum increase in the FF was nearly $33 \%(\mathrm{FF}=75 \%)$ and the maximum increase in PCE was $46 \%$ (PCE $=8.6 \%)$, respectively. We attribute this improvement in the device performance to a decrease in the series resistance and an increase in the shunt resistance. Intensity dependence of current-voltage characteristics shows suppression of the trap assisted recombination at short circuit leads to increased charge collection. An increase in the built-in potential $\left(\mathrm{V}_{\mathrm{bi}}\right)$ after insertion of the Ba layer due to the lower work function of $\mathrm{Ba}(2.7 \mathrm{eV})$, compared to $\mathrm{Al}(4.3 \mathrm{eV})$ further assists faster sweep-out. Ba shows excellent hole-blocking even at high baises and outperforms all the other reported cathode interlayers in improving the device fill factor.

\section{Methods}

Device fabrication. The SM-BHJ solar cells were prepared by several experimental steps. First the ITO substrate $(20 \Omega / \mathrm{sq})$ was cleaned by detergent, acetone and isopropyl alcohol with ultra-sonication. After exposing the cleaned ITO to the UV/ozone treatment for $15 \mathrm{~min}$. to reform the surface, the hole transport material of PEDOT:PSS (Clevious PH) was spin-coated at $5000 \mathrm{rpm}$ for $40 \mathrm{~s}$ to obtain the film thickness of $\sim 30 \mathrm{~nm}$. The p-DTS(FBTTh $)_{2}: \mathrm{PC}_{71} \mathrm{BM}$ (donor:acceptor) blend solution was prepared from the weight ratio of $60: 40$ and total $35 \mathrm{mg} / \mathrm{ml}$ in CB with $0.4 \mathrm{v} \%$ of DIO processing additive. After stirring overnight at $60^{\circ} \mathrm{C}$, the blend was heated to $90^{\circ} \mathrm{C}$ for $15 \mathrm{~min}$ before spin casting. The BHJ film was obtained from spin casting the solution at $2000 \mathrm{rpm}$ for $60 \mathrm{~s}$. The coated BHJ films were baked to $80^{\circ} \mathrm{C}$ for $10 \mathrm{~min}$ to evaporate residual solvent. Before deposition, Ba was evaporated under vacuum condition of $4 \times 10^{-6}$ torr without substrate for few minutes to remove any 

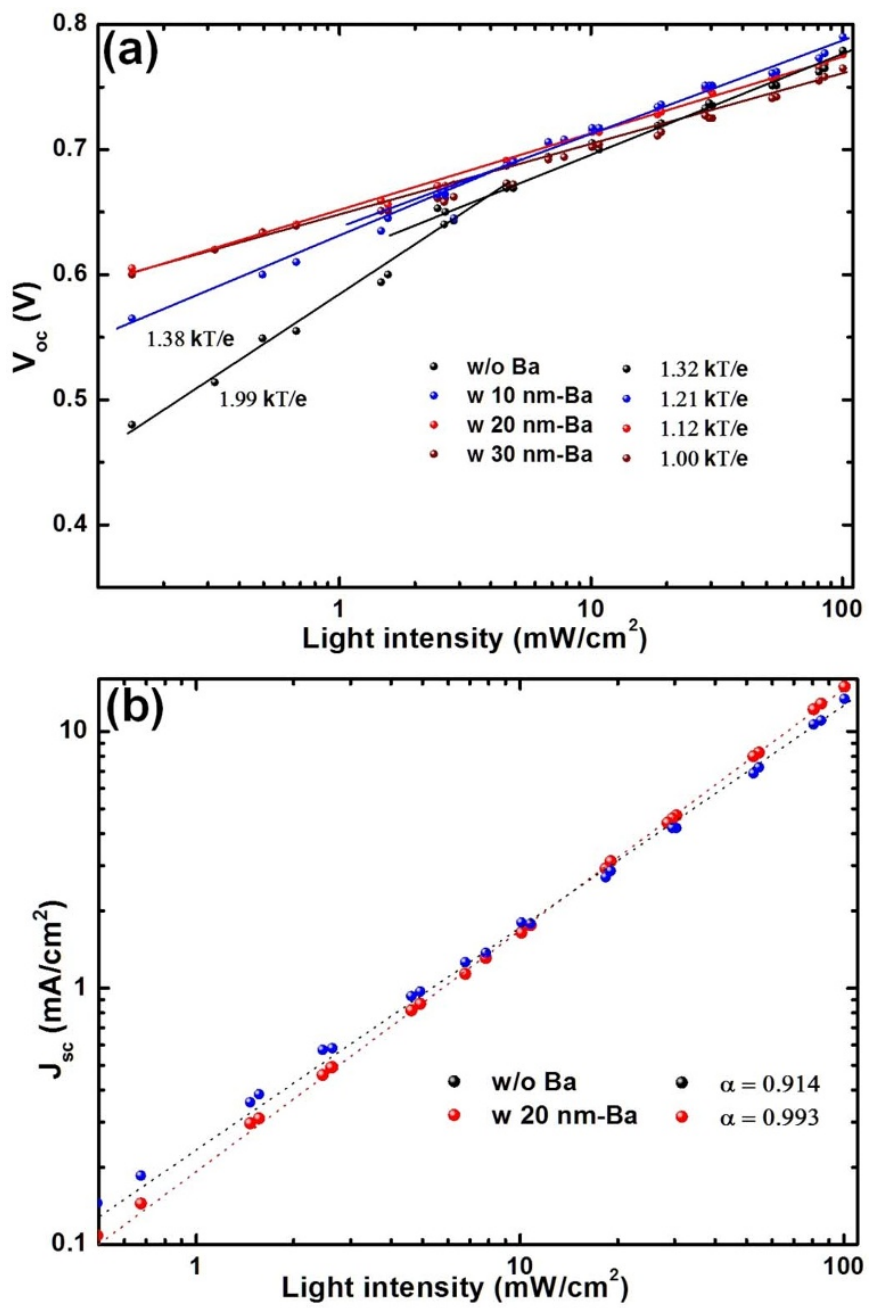

Figure $5 \mid$ (a) The measured $V_{o c}$ of p-DTS( FBTTh $\left._{2}\right)_{2}: \mathrm{PC}_{71} \mathrm{BM}$ solar cells with $\mathrm{Ba} 0 \mathrm{~nm}, 10 \mathrm{~nm}, 20 \mathrm{~nm}$ and $30 \mathrm{~nm}$ as a function of illumination intensity (symbols), together with linear fits to the data (solid lines). (b) Measured $\mathrm{J}_{\mathrm{sc}}$ of p-DTS $\left(\mathrm{FBTTh}_{2}\right)_{2} / \mathrm{PC}_{71} \mathrm{BM} \mathrm{BHJ}$ solar cells without Ba and with $20 \mathrm{~nm}$ Ba ploted against light intensity (symbol) on the logarithmic scale and fitted power law (line) yield $\alpha$.

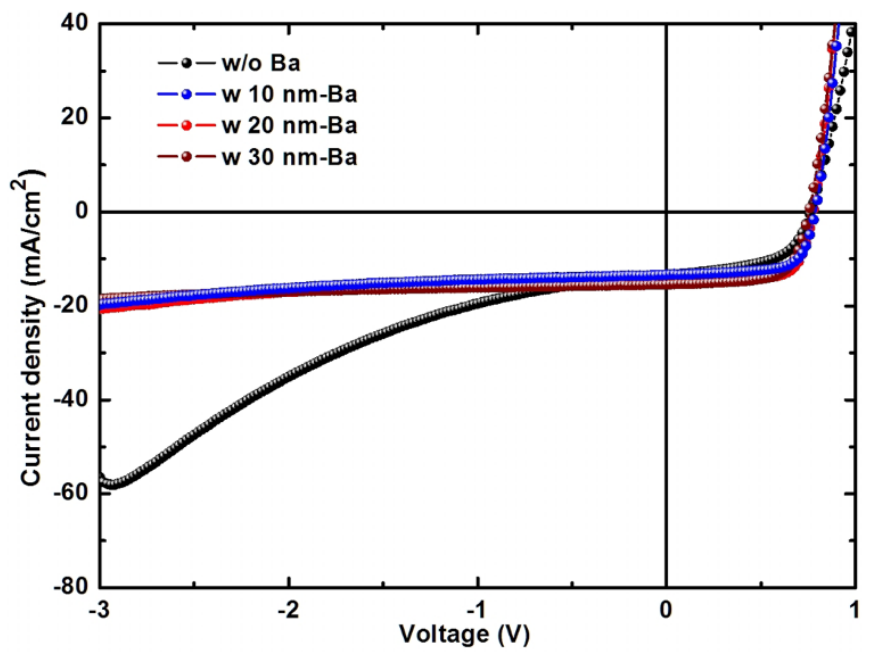

Figure $6 \mid$ (a) $J-V$ characteristics of the p-DTS $\left(\mathrm{FBTTh}_{2}\right)_{2} / \mathrm{PC}_{71} \mathrm{BM} \mathrm{BHJ}$ solar cells with Ba $0 \mathrm{~nm}, 10 \mathrm{~nm}, 20 \mathrm{~nm}$ and $30 \mathrm{~nm}$ under AM $1.5 \mathrm{G}$ irradiation at $100 \mathrm{~mW} / \mathrm{cm}^{2}$. oxide impurity from its surface. After Ba deposition (10, 20,30 nm), the Al cathode was deposited to $\sim 100 \mathrm{~nm}$ at the same vacuum condition of $4 \times 10^{-6}$ torr. The fabricated solar cells were encapsulated with epoxy and cover glass.

Device measurements. The $J-V$ characteristics of the solar cells were measured by a Keithley 2400 sourcemeter unit. The light source was calibrated by using silicon reference cells with an AM $1.5 \mathrm{G}$ solar simulator with an intensity of $100 \mathrm{~mW} / \mathrm{cm}^{2}$. During the testing, an aperture with an area of $4.5 \mathrm{~mm}^{2}$ (total electrode size $5 \mathrm{~mm}^{2}$ ) was used to accurately measure the performance of solar cells. In order to test the solar cells under various light intensities, the intensity of the light was modulated with a series of two neutral density filters wheels of six filters apiece, allowing for up to 35 steps in intensity from 100 to $0.1 \mathrm{~mW} / \mathrm{cm}^{2}$. The intensity of light transmitted through the filter was independently measured via a power meter. All solar cells were tested in ambient air.

1. Yu, G., Gao, J., Hummelen, J. C., Wudl, F. \& Heeger, A. J. Polymer photovoltaic cells: Enhanced efficiencies via a network of internal donor-acceptor heterojunctions. Science 270, 1789-1791 (1995).

2. Li, G. et al. High-efficiency solution processable polymer photovoltaic cells by selforganization of polymer blends. Nat Mater 4, 864-868 (2005).

3. Ma, W., Yang, C., Gong, X., Lee, K. \& Heeger, A. J. Thermally stable, efficient polymer solar cells with nanoscale control of the interpenetrating network morphology. Adv Funct Mater 15, 1617 (2005).

4. Li, G., Zhu, R. \& Yang, Y. Polymer solar cells. Nat Photon 6, 153-161 (2012).

5. Zhao, G., He, Y. \& Li, Y. 6.5\% Efficiency of polymer solar cells based on poly(3hexylthiophene) and jndene-C60 bisadduct by device optimization. Adv Mater 22, 4355-4358 (2010).

6. He, Z. et al. Simultaneous enhancement of open-circuit voltage, short-circuit current density, and fill factor in polymer solar cells. Adv Mater 23, 4636-4643 (2011).

7. Liang, Y. et al. For the Bright Future-Bulk Heterojunction Polymer Solar Cells with Power Conversion Efficiency of 7.4\%. Adv Mater 22, E135-E138 (2010).

8. Sun, Y. et al. Solution-processed small-molecule solar cells with $6.7 \%$ efficiency. Nat Mater 11, 44-48 (2012).

9. van der Poll, T. S., Love, J. A., Nguyen, T.-Q. \& Bazan, G. C. Non-basic highperformance molecules for solution-processed organic solar cells. Adv Mater 24, 3646-3649 (2012).

10. Kyaw, A. K. K. et al. Efficient solution-processed small-molecule solar cells with inverted structure. Adv Mater 25, 2397-2402 (2013).

11. Li, W. et al. Efficient small bandgap polymer solar cells with high fill factors for $300 \mathrm{~nm}$ thick films. Adv Mater 25, 2397-2402 (2013).

12. Park, S. H. et al. Bulk heterojunction solar cells with internal quantum efficiency approaching $100 \%$. Nat Photon 3, 297-302 (2009).

13. Lee, J. H., Cho, S., Roy, A., Jung, H.-T. \& Heeger, A. J. Enhanced diode characteristics of organic solar cells using titanium suboxide electron transport layer. Applied Physics Letters 96, 163303 (2010).

14. Li, G., Chu, C.-W., Shrotriya, V., Huang, J. \& Yang, Y. Efficient inverted polymer solar cells. Appl Phys Lett 88, 253503 (2006).

15. Zhao, D. W. et al. An inverted organic solar cell with an ultrathin Ca electrontransporting layer and MoO[sub 3] hole-transporting layer. Appl Phys Lett 95, 153304 (2009).

16. White, M. S., Olson, D. C., Shaheen, S. E., Kopidakis, N. \& Ginley, D. S. Inverted bulk-heterojunction orgnaic photovoltaic device using a solution-derived $\mathrm{ZnO}$ underlayer. Appl Phys Lett 89, 143517 (2006).

17. Kyaw, K. K. A. et al. Intensity dependence of curent-voltage characteristics and recombination in high-efficiency solution processeed small molecule solar cells. ACS Nano. DOI: $10.1021 / \mathrm{nn} 401267 \mathrm{~s}$.

18. Wang, D. H., Kyaw, K. K. A., Gupta, V., Bazan, G. C. \& Heeger, A. J. enhanced efficiency parameters of solution processable small molecule solar cells depending on the ITO sheet resistance. Adv. Energy Mater. DOI: 10.1002/aenm.201300277.

19. Brabec, C. J., Shaheen, S. E., Winder, C., Sariciftci, N. S. \& Denk, P. Effect of $\mathrm{LiF} /$ metal electrodes on the performance of plastic solar cells. Appl Phys Lett $\mathbf{8 0}$, $1288-1290$ (2002).

20. Yang, X. et al. Nanoscale morphology of high-performance polymer solar cells. Nano Lett 5, 579-583 (2005).

21. Peumans, P., Yakimov, A. \& Forrest, S. R. Small molecular weight organic thinfilm photodetectors and solar cells. J Appl Phys 93, 3693-3723 (2003).

22. Chang, C.-C. et al. Effects of cathode buffer layers on the efficiency of bulkheterojunction solar cells. Appl Phys Lett 96, 263506 (2010).

23. Yip, H.-L., Hau, S. K., Baek, N. S., Ma, H. \& Jen, A. K. Y. Polymer solar cells that use self-assembled-monolayer-modified $\mathrm{ZnO} /$ metals as cathodes. Adv Mater 20 , 2376-2382 (2008).

24. Luo, J. et al. Enhanced open-circuit voltage in polymer solar cells. Appl Phys Lett 95, 043301 (2009).

25. He, C. et al. Origin of the enhanced open-circuit voltage in polymer solar cells via interfacial modification using conjugated polyelectrolytes. J Mater Chem $\mathbf{2 0}$, 2617-2622 (2010).

26. Seo, J. H. et al. Improved high-efficiency organic solar cells via incorporation of a conjugated polyelectrolyte interlayer. J Am Chem Soc 133, 8416-8419 (2011). 
27. Oh, S.-H. et al. Water-soluble polyfluorenes as an interfacial layer leading to cathode-independent high performance of organic solar cells. Adv Funct Mater 20, 1977-1983 (2010).

28. He, Z. et al. Enhanced power-conversion efficiency in polymer solar cells using an inverted device structure. Nat Photon 6, 591-595 (2012).

29. Cowan, S. R., Roy, A. \& Heeger, A. J. Recombination in polymer-fullerene bulk heterojunction solar cells. Phys Rev B 82, 245207 (2010).

30. Koster, L. J. A., Kemerink, M., Wienk, M. M., Maturová, K. \& Janssen, R. A. J. Quantifying bimolecular recombination losses in organic bulk heterojunction solar cells. Adv Mater 23, 1670-1674 (2011).

31. Pal, S. K. et al. Geminate charge recombination in polymer/fullerene bulk heterojunction films and implications for solar cell function. J Am Chem Soc 132, 12440-12451 (2010)

32. Shockley, W. \& Read, W. T., Jr. Statistics of the Recombinations of Holes and Electrons. Phys Rev 87, 835-842 (1952).

33. Hall, R. N. Electron-Hole recombination in germanium. Phys Rev 87, 387-387 (1952)

34. Credgington, D., Jamieson, F. C., Walker, B., Nguyen, T.-Q. \& Durrant, J. R. Quantification of geminate and non-geminate recombination losses within a solution-processed small-molecule bulk heterojunction solar cell. Adv Mater 24, 2135-2141 (2012)

35. Proctor, C. M., Kim, C., Neher, D. \& Nguyen, T.-Q. Nongeminate recombination and charge transport limitations in diketopyrrolopyrrole-based solutionprocessed small molecule solar cells. Adv Funct Mater, doi:10.1002/ adfm.201202643 (2013).

36. Mandoc, M. M., Veurman, W., Koster, L. J. A., de Boer, B. \& Blom, P. W. M. Origin of the reduced fill factor and photocurrent in MDMO-PPV:PCNEPV all-polymer solar cells. Adv Funct Mater 17, 2167-2173 (2007).

37. Koster, L. J. A., Mihailetchi, V. D., Ramaker, R. \& Blom, P. W. M. Light intensity dependence of open-circuit voltage of polymer:fullerene solar cells. Appl Phys Lett 86, 123509 (2005).

38. Riedel, I. et al. Effect of temperature and illumination on the electrical characteristics of polymer-fullerene bulk-heterojunction solar cells. Adv Funct Mater 14, 38-44 (2004).
39. Schilinsky, P., Waldauf, C. \& Brabec, C. J. Recombination and Loss Analysis in Polythiophene Based Bulk Heterojunction Photodetectors. Appl. Phys. Lett. 81 3885-3887 (2002).

40. Van Duren, J. K. J. et al. Relating the Morphology of Poly(p-phenylene vinylene)/ Methanofullerene Blends to Solar-Cell Performance. Advanced Functional Materials 14, 425-434 (2004).

\section{Acknowledgments}

This research was carried out at UCSB with support from the Department of Energy under a grant titled "Charge Recombination, Transport Dynamics, and Interfacial Effects in Organic Solar Cells”; DOE \#DE-FG02-08ER46535 . V.G. thanks financial support from Indo-US Science and Technology Forum (IUSSTF), Award No. Indo-US Research Fellowship/2012-2013/26-2012. A.K.K.K. thanks Agency for Science Technology and Research (A*STAR) of Singapore for a postdoctoral fellowship.

\section{Author contributions}

A.J.H. suggested the idea of the project. V.G. did device fabrication, measurement, data analysis and characterization with the support of A.K.K.K. and D.H.W. All authors actively participated in the discussion, and V.G. wrote the initial draft of the manuscript, A.J.H., G.C.B. and S.C. were involved in discussion, supervised the project and wrote the final draft of the manuscript. All the authors reviewed the manuscript.

\section{Additional information}

Competing financial interests: The authors declare no competing financial interests.

How to cite this article: Gupta, V. et al. Barium: An Efficient Cathode Layer for Bulk-heterojunction Solar Cells. Sci. Rep. 3, 1965; DOI:10.1038/srep01965 (2013).

(c) (i) $(9)$ This work is licensed under a Creative Commons Attribution-

cc. license, visit http://creativecommons.org/licenses/by-nc-nd/3.0 